\title{
Neurociência cognitiva na sala de aula: estratégias de ensino de Língua Espanhola
}

\author{
Cognitive neuroscience in the classroom: teaching strategies in Spanish Language
}

\author{
Louise Silva do Pinho \\ Universidade Federal do Pampa, Bagé, RS, Brasil
}

$\diamond$

\begin{abstract}
Resumo: Apresentamos, neste artigo, uma análise de atividades de um material didático elaborado para o ensino de leitura em Língua Espanhola (PINHO, 2015b) que tem como base conceitos da Neurociência Cognitiva (COSENZA; GUERRA, 2011) e do ensino e aprendizagem de leitura (LEFFA, 1996; SCHLATTER, 2009). O objetivo deste trabalho é analisar algumas atividades e estratégias de ensino de Língua Espanhola utilizadas em aulas aplicadas pela pesquisadora na referida pesquisa e observar como elas contribuem com o ensino e a aprendizagem de leitura em língua espanhola. A análise das atividades foi feita com base nos conceitos neurocientíficos de funções cognitivas (percepção, memória, funções executivas e funções expressivas) e em estudos sobre o desenvolvimento da habilidade da leitura. Foi possível verificar que as atividades de compreensão leitora analisadas buscam desenvolver as funções cognitivas durante o processo de aprendizagem da leitura em língua espanhola, além de estimularem o uso de estratégias de leitura.
\end{abstract}

Palavras-chave: Neurociência cognitiva; Leitura; Língua espanhola

\begin{abstract}
In this article, we present an analysis of the activities of a didactic material developed for teaching reading in Spanish (PINHO, 2015b), based on concepts of Cognitive Neuroscience (COSENZA; GUERRA, 2011) and reading teaching and learning (LEFFA, 1996; SCHLATTER, 2009). The objective of this paper is to analyze some activities and strategies of teaching Spanish Language used in classes applied by the researcher in the mentioned research and to observe how they contribute with the teaching and learning of reading in Spanish language. The analysis of the activities was based on the neuroscientific concepts of cognitive functions (perception, memory, executive functions and expressive functions) and on studies about the development of reading ability. It was possible to verify that the activities of reading comprehension analyzed seek to develop cognitive functions during the process of learning to read in Spanish, besides to stimulating the use of reading strategies.
\end{abstract}

Keywords: Cognitive Neuroscience; Reading; Spanish language

\section{Introdução}

A busca por metodologias, estratégias e novas formas de ensinar e de aprender é frequente entre professores que procuram aperfeiçoar sua prática docente e também entre estudantes que desejam melhorar seu desempenho. Tudo o que fazemos, o que percebemos e o que pensamos depende do nosso cérebro para existir ou para acontecer. Assim, em consonância com Cosenza e Guerra (2011), consideramos positivo o diálogo entre a educação e as neurociências na busca pelo sucesso nas práticas pedagógicas, já que "as estratégias pedagógicas que respeitam a forma como o cérebro funciona tendem a ser mais eficientes" (COSENZA; GUERRA, 2011, p. 143).

A aprendizagem ocorre porque há, no cérebro, mecanismos que permitem a realização de processos relacionados à cognição, como as funções cognitivas, responsáveis pela atenção, pela memória, pelo processamento das informações e pelo uso da linguagem. Ela também é resultado da capacidade que o cérebro tem de se modificar, "de alterar a sua função ou a sua estrutura em resposta às influências ambientais que o atingem" (LENT, 
2015, p. 112), o que chamamos de neuroplasticidade. Essas influências ambientais são representadas, na sala de aula, pelos estímulos (atividades, exercícios, metodologias) dados pelo professor, que podem ser mais ou menos produtivos, de acordo com os objetivos que se pretende atingir, a forma como cada tarefa é organizada e como os alunos são preparados para sua realização.

Apresentaremos, neste artigo, uma análise de atividades de aulas de língua espanhola presentes em um protótipo de material didático que foi produto de uma pesquisa desenvolvida durante o curso de Mestrado em Ensino de Línguas que compôs a dissertação de mestrado intitulada "Filosofia Bakhtiniana da Linguagem e Neurociências em diálogo: uma proposta para o ensino de leitura em língua espanhola" (PINHO, 2015a). Esse trabalho tinha como objetivo propor alternativas para o ensino de leitura em Língua Espanhola que tivessem como base os estudos neurocientíficos, ou seja, que considerassem o conhecimento existente sobre o funcionamento do cérebro humano no processo de desenvolvimento cognitivo.

O objetivo deste artigo é, a partir da referida pesquisa, discutir algumas atividades e estratégias de ensino de Língua Espanhola utilizadas no decorrer das aulas ministradas pela professora-pesquisadora e observar como cada tipo de atividade pode contribuir para o exercício das funções cognitivas dos alunos. Verificaremos de que forma o uso de estratégias que considerem o processo executado pelo cérebro na cognição podem contribuir com o ensino e a aprendizagem de leitura em Língua Espanhola, tendo em vista o que estudos sobre Neurociência Cognitiva dizem sobre as funções cognitivas.

O conhecimento dessas estratégias e da forma como são utilizadas em aula para ensinar leitura em Língua Espanhola pode servir para que outros professores também as utilizem, adaptando-as a outros contextos de ensino, criando outras atividades que contenham os mesmos elementos mas que possam ser voltadas a outras necessidades de aprendizagem.

\section{Aporte teórico}

Este estudo baseia-se em conceitos das Neurociências, mais especificamente a Neurociência Cognitiva, e sua interface com a educação, discutida por Cosenza e Guerra (2011), como as funções cognitivas, ativadas pelo cérebro em qualquer processo de aprendizagem. Também discutiremos conceitos relacionados à leitura e ao desenvolvimento da compreensão leitora em língua adicional, com base em Leffa (1996) e Schlatter (2009), entre outros autores.

As Neurociências são classificadas em cinco grandes disciplinas, de acordo com a maneira como abordam o estudo do sistema nervoso. A Neurociência Cognitiva, que também pode ser chamada de Neuropsicologia, conforme Lent (2010), é uma dessas cinco disciplinas, e se ocupa de capacidades mentais complexas, como a linguagem, por exemplo, e a leitura, como uma das habilidades linguísticas que podem ser desenvolvidas pelo ser humano.

É possível aprender, desenvolver habilidades e adquirir conhecimentos graças à capacidade que o cérebro possui de modificar-se. A aprendizagem consiste em modificar o cérebro por meio da prática pedagógica, compreendendo-o como um "órgão social" (RELVAS, 2012, p. 15). Essa modificação é possível devido à neuroplasticidade cerebral, que é a capacidade que o cérebro tem de, por meio da interação social ou de estímulos do ambiente, "modificar, de modo permanente ou pelo menos prolongado, a sua função e a sua forma" (LENT, 2002, p. 148). O ser humano possui fases em que essa reorganização do cérebro é mais suscetível, os chamados períodos críticos. A aquisição da linguagem é o exemplo de período crítico mais duradouro em seres humanos, segundo Lent (2015), que pode durar até a adolescência. Porém, o final desses períodos não significa que o cérebro perdeu completamente sua plasticidade, ela estende-se até a maturidade, apenas ocorre de forma diferente. A neuroplasticidade é considerada fundamental para a aprendizagem, já que é graças a ela que o cérebro é capaz de armazenar informações, "sendo considerada a base funcional da memória" (LENT, 2015, p. 112).

A cognição pode ser entendida como a aquisição de conhecimento e envolve todos os processos pelos quais as informações passam até serem transformadas, armazenadas e, posteriormente, recuperadas, conforme Relvas (2012). Há um conjunto de operações realizadas pelo cérebro que fazem parte do processo de aprendizagem e que devem ser consideradas pelo professor ao fazer seus planejamentos e conduzir suas aulas.

A consciência central focaliza e intensifica a atenção e a memória operacional, favorece o estabelecimento de memórias, é indispensável para as operações normais de linguagem e aumenta a abrangência das manipulações inteligentes que denominamos planejamento, resolução de problemas e criatividade (DAMÁSIO, 2000, p. 165).

As operações mencionadas pelo autor constituem o que chamamos de funções cognitivas, que são compostas pelas funções receptivas, funções retentivas, funções executivas e funções expressivas, conforme Maia (2011).

As funções receptivas são as responsáveis por receber e dar significado às informações e constituem a percepção, que é "a capacidade de associar as informações sensoriais à memória e à cognição, de modo a formar 
conceitos sobre o mundo e sobre nós mesmos" (LENT, 2010, p. 612). A fim de aperfeiçoar esse mecanismo, o ser humano conta com a atenção, que é, de acordo com Lent (2010), a capacidade de focalizar a consciência, ou seja, de selecionar aquilo que é mais importante e colocar os demais estímulos em segundo plano.

A atenção pode ser classificada em explícita, quando o seu foco coincide com a fixação visual, e implícita, quando não coincide. Ela também pode ser classificada de acordo com o tempo em que é mantida ou à forma como é direcionada aos diferentes estímulos ou tarefas, segundo Maia (2011): a vigilância é a capacidade de reagir a estímulos prontamente; a atenção passiva referese a atividades automatizadas, mas das quais temos consciência; a atenção sustentada é a que precisa ser mantida por um longo período de tempo; a atenção seletiva é a que é direcionada apenas a um estímulo no ambiente; a atenção dividida é a capacidade de alternar entre mais de um estímulo com igual eficiência. A atenção, na sala de aula, é necessária o tempo todo para que o aluno tenha um bom desempenho no seu processo de aprendizagem. Por isso, o professor pode usar estratégias metodológicas que promovam o exercício da atenção. Também é preciso considerar que há diversos fatores que podem interferir negativamente na capacidade de atenção de um indivíduo, como o interesse pela tarefa que deve ser desempenhada, sua complexidade, seu nível de consciência, além de aspectos afetivos.

A memória faz parte das funções retentivas, responsáveis pelo armazenamento de informações que possam ser posteriormente recuperadas e utilizadas. Ela é diferente da aprendizagem, que corresponde ao processo de aquisição das informações, conforme Lent (2010). Segue-se a ela a retenção, que pode ocorrer por períodos curtos ou longos, mas, nos dois casos, as informações podem ser recuperadas ou esquecidas. Há vários tipos de memória, segundo Lent (2010):

Levando em conta o tempo de retenção, podese considerar a memória ultrarrápida, de curta duração e longa duração. Já quanto à sua natureza, podemos considerar as memórias implícita, explícita e operacional. A primeira é a memória dos hábitos, procedimentos e regras de representação perceptual, a aprendizagem associativa e a não associativa, todas formas de memória que não precisam ser descritas com palavras para serem evocadas. Em contraposição, a memória explícita costuma ser descrita com palavras ou outros símbolos, e consiste em um subtipo chamado episódico (a memória dos fatos que ocorrem ao longo do tempo) e um subtipo chamado semântico (a memória dos conceitos atemporais). Finalmente, a memória operacional é a que nos serve para a utilização rápida no raciocínio e no planejamento do comportamento. (LENT, 2010, p. 644)
Na sala de aula, segundo o autor, a consolidação da aprendizagem ocorre por meio de associações entre o novo conhecimento e o que já se sabe, aquilo que já está armazenado na memória, pois as informações, no cérebro, são organizadas em forma de mapas. Dessa forma, é possível armazenar mais informações e recuperá-las mais facilmente se estiverem associadas umas às outras. Outro fator que regula a memória são as emoções, que podem enfraquecê-la ou fortalecê-la, conforme Lent (2010). Memorizamos com mais facilidade fatos ou informações que possuam uma forte carga emocional para nós, seja positiva ou negativa. Além disso, a atenção também é um importante modulador da memória, pois lembramos mais facilmente de informações ou fatos importantes quando focalizamos nossa atenção neles.

As funções executivas, de acordo com Maia e Costa (2011), são as responsáveis pelo processamento da informação, e dela fazem parte a atenção, a memória de trabalho, a volição, o planejamento, a ação propositiva e a verificação de desempenho. São elas que "possibilitam nossa interação com o mundo frente às mais diversas situações que encontramos" (COSENZA; GUERRA, 2011, p. 87). Por meio das funções cognitivas organizamos nosso pensamento, considerando o que temos armazenados na nossa memória e nossos objetivos e expectativas para o futuro e, dessa forma, "podemos estabelecer estratégias comportamentais e dirigir nossas ações de uma forma objetiva, mas flexível, que permita, ao final, chegar ao objetivo desejado" (COSENZA; GUERRA, 2011, p. 87). As funções executivas são importantes para a realização de qualquer tarefa apresentada na sala de aula, além de serem fundamentais para organizar o estudo e definir metas de aprendizagem.

Por fim, temos as funções expressivas, a linguagem oral, a escrita ou atos motores complexos que, embora tenham sido assim classificadas, fazem parte de todas as demais funções, já que todas elas são mediadas pela linguagem. Conforme Maia (2011), a linguagem é processada no cérebro de forma modular, "apresenta redes específicas para o processamento de níveis hierarquizados" (MAIA, 2011, p. 37). Esses níveis correspondem aos fonemas, as palavras, aos significados, à sintaxe, à pragmática e à prosódia. Além disso, as intenções e as emoções, bem como o contexto e as características do sujeito que enuncia, influenciam a produção de discurso e o uso da linguagem em qualquer situação.

A linguagem caracteriza os seres humanos. O aparecimento da linguagem falada remonta a milhares de anos e a linguagem verbal "deixou marcas em nosso cérebro, onde podemos encontrar circuitos especializados no processamento da linguagem" (COSENZA; GUERRA, 2011, p. 99), como a Área de Broca, relacionada à expressão da linguagem, e a Área de Wernicke, relacionada 
à compreensão da linguagem. A linguagem escrita, incluída nela a leitura de textos, no entanto, não conta com aparatos específicos no cérebro humano, em função de sua aquisição ter sido mais recente. Por isso, "ela precisa ser ensinada, ou seja, é necessário o estabelecimento de circuitos cerebrais que a sustentem, o que se faz por meio de dedicação e exercício" (COSENZA; GUERRA, 2011, p. 101), de modo que estruturas responsáveis por outras funções são utilizadas para o processamento da linguagem escrita. Assim, aprender a ler modifica nosso cérebro de forma permanente.

O modelo de dupla via, ou de dupla rota, descreve a leitura das palavras de forma precisa, de acordo com Cosenza e Guerra (2011). Conforme esse modelo, "a palavra pode passar por duas vias para ser decodificada em termos da linguagem" (COSENZA; GUERRA, 2011, p. 102): uma via grafo-fonológica e uma via global (forma visual da palavra). A primeira se refere à decodificação das letras em sons, que pode ocorrer tanto na leitura silenciosa como na leitura em voz alta; já a segunda via se refere ao reconhecimento das palavras como imagens, que é uma "decodificação direta, um reconhecimento imediato da área da forma visual da palavra" (COSENZA; GUERRA, 2011, p. 103). As duas vias podem ser ativadas durante a leitura de textos, mas podem existir diferenças em sua ativação, de acordo com a língua em que a leitura é realizada. Conforme Frost (2013), há línguas em que a relação entre grafemas e fonemas, tanto na leitura quanto na escrita, é mais opaca, como o inglês. Já línguas como o espanhol e o italiano "são totalmente transparentes em ambas as direções" (FROST, 2013, p. 298).

No entanto, a leitura não é apenas decodificação, apesar de essa ser uma etapa muito importante. De acordo com Leffa (1996), a leitura é

um processo extremamente complexo, composto de inúmeros subprocessos que se encadeiam de modo a estabelecer canais de comunicação por onde, em via dupla, passam inúmeras informações entre o leitor e o texto. (LEFFA, 1996, p. 24)

Para o autor, a leitura é um processo de interação entre texto e leitor, que envolve desde o reconhecimento das palavras (nível fonológico), a formação das orações (nível sintático), a estruturação dos parágrafos, do texto em sua totalidade, até o nível do sentidos, do contexto, passando pela intencionalidade do leitor ao realizar a leitura. Além disso, os conhecimentos prévios do leitor também são muito importantes para que seja feita a correspondência entre as informações já conhecidas e as que o texto apresenta.

No entanto, a participação do leitor não ocorre somente no momento de ler, mas também durante o processo de aprendizagem da leitura, segundo Leffa
(1996). "A capacidade que temos de refletir sobre o que fazemos pode também nos ajudar a desenvolver estratégias adequadas de leitura" (LEFFA, 1996, p. 45). As estratégias de leitura são procedimentos realizados pelo leitor para solucionar problemas que ele encontra ao ler determinado texto, que podem estar relacionados a diferentes níveis: fonológico, lexical ou contextual, por exemplo. A reflexão sobre o próprio processo de leitura e o uso de estratégias fazem parte do campo da metacognição, que envolve "a habilidade para monitorar a própria compreensão" (LEFFA, 1996, p. 46) e é um processo totalmente consciente. O processo cognitivo relacionado à aprendizagem da leitura também varia de acordo com o indivíduo, com o contexto, com os objetivos que possui para aprender determinado idioma e com a motivação que tem para realizar uma determinada tarefa.

Para Schlatter (2009), todos os processos cognitivos

ocorrem sempre de forma integrada (e não ordenada) no processo de leitura, e o conhecimento necessário para desempenhar essas ações de forma integrada pode ser aprendido pelas práticas de leitura cotidianas e deve ser ensinado e sistematizado na escola (SCHLATTER, 2009, p. 13).

De acordo com a autora, a aprendizagem de línguas estrangeiras ${ }^{1}$ no ensino básico deve buscar promover o letramento também em outras línguas diferentes da língua materna, a fim de ampliar suas possibilidades de interação em nossa sociedade, o que faz parte da formação dos alunos como cidadãos. A partir dessa perspectiva, a leitura é vista como uma prática social, na qual o leitor interage por meio de diferentes gêneros discursivos, conceito de Bakhtin (2011). Para que essa perspectiva esteja presente de forma efetiva na sala de aula e nos materiais utilizados para o ensino de leitura, Schlatter (2009) propõe alguns critérios: a seleção de temas norteadores para as atividades que sejam relevantes para os alunos em seus respectivos contextos; considerar o caráter dialógico dos gêneros discursivos na elaboração das atividades; selecionar leituras coerentes com os temas escolhidos; decidir as habilidades linguísticas que devem ser trabalhadas; desenvolver as tarefas em diferentes etapas (preparação, compreensão, produção, por exemplo); refletir sobre aspectos culturais; entre outros.

\footnotetext{
1 Usamos o termo "línguas estrangeiras" neste ponto por ser o termo usado pela autora no artigo citado. No entanto, consideramos que as orientações dadas por ela para a elaboração dos materiais também é adequada ao ensino que parte da noção de línguas adicionais, o que pode ser verificado nas propostas para o ensino de línguas adicionais apresentadas em Schlatter e Garcez (2012).
} 


\section{Metodologia}

Analisaremos, neste artigo, atividades presentes no material didático “¡Léelo ahora! Prácticas de lectura en lengua española" (PINHO, 2015b), que é o produto pedagógico resultante da pesquisa de mestrado apresentada em Pinho (2015a). Esse material didático foi utilizado em um curso oferecido pelo projeto de extensão "Núcleo de Línguas Adicionais", da Universidade Federal do Pampa (Unipampa), entre os anos de 2014 e 2015. O projeto é vinculado ao curso de Licenciatura em Letras Línguas Adicionais e oferece cursos de Inglês e Espanhol à comunidade acadêmica e externa de forma gratuita. $\mathrm{O}$ curso no qual realizou-se a pesquisa que gerou o material que analisaremos neste artigo foi composto por quatro módulos e teve, no total, noventa horas de duração, com aulas semanais de duas horas. Dois módulos eram de nível básico e os dois seguintes de nível intermediário.

Nos cursos, ambas as línguas são abordadas a partir da noção de língua adicional, que são línguas que são acrescentadas ao repertório linguístico do estudante por serem necessárias para o exercício da cidadania na sociedade contemporânea, além de serem línguas usada para a comunicação transnacional, conforme Schlatter e Garcez (2012). Além disso, o ensino de Inglês e Espanhol no contexto brasileiro faz parte de um processo de formação de cidadãos críticos e participativos e de inclusão dos alunos por meio do acesso a discursos organizados em outras línguas, que fazem parte do mundo globalizado e que influenciam suas vidas. De acordo com Leffa e Irala (2014), o uso do termo língua estrangeira "já não se sustenta mais no caso do espanhol e do inglês no Brasil, por fazerem parte de uma realidade que nos é familiar" (LEFFA; IRALA, 2014, p. 29). Por isso, em consonância com o projeto no qual os dados analisados foram coletados, optamos por usar o termo línguas adicionais neste artigo.

As atividades analisadas neste artigo foram extraídas de um protótipo de material didático para aulas de língua espanhola, intitulado "¿Léelo ahora! Prácticas de lectura en lengua española" (PINHO, 2015b). Esse material constitui um produto pedagógico resultante da pesquisa realizada em Pinho (2015a). Buscamos selecionar, para a análise, atividades voltadas especificamente para a compreensão leitora e o uso de estratégias de leitura.

A análise que pretendemos fazer é qualitativa e caracteriza-se como uma pesquisa descritiva do tipo análise documental. Selecionaremos, no referido material, algumas atividades voltadas à leitura que exercitem uma ou mais funções cognitivas dentro da sua unidade didática, ou que representem estratégias de aprendizagem da leitura entre os exercícios, e que sejam passíveis de adaptação a outros contextos. Analisaremos, então, essas atividades, descrevendo, com base nos conceitos de Neurociências apresentados anteriormente, como essas atividades e estratégias contribuem para a aprendizagem de leitura em Língua Espanhola.

\section{Discussão dos resultados}

Discutiremos, nesta seção, alguns elementos, estratégias e atividades presentes em Pinho (2015b). O material está formado por dez unidades, cada uma delas composta por um tema norteador e uma ou mais leituras de diferentes gêneros discursivos, em consonância com as propostas de Schlatter (2009), além de determinado vocabulário e tópico gramatical, conforme Figura 1.
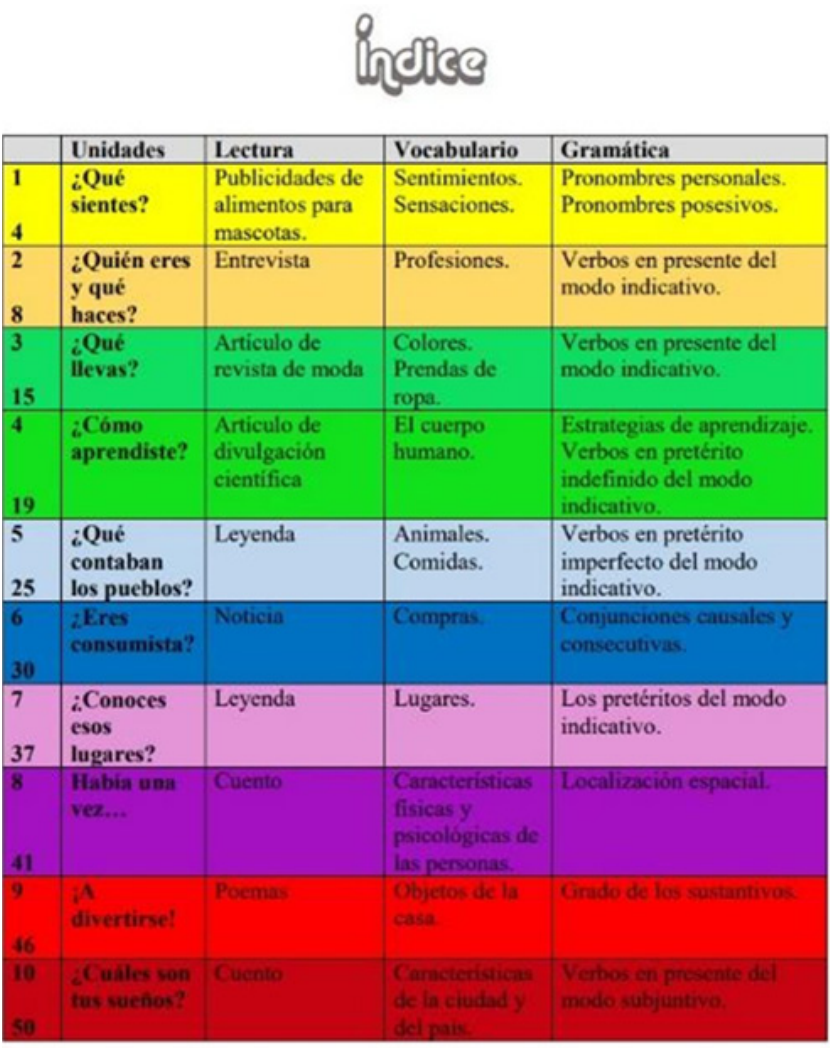

Figura 1. Índice de Pinho (2015b).

Cabe ressaltar que, apesar de a compreensão leitora ser a destreza linguística que norteia o material, todas as demais destrezas estão presentes nas atividades. Outro aspecto que deve ser mencionado é que as dez unidades observadas na Fig. 1 são apenas uma seleção de materiais aplicados no curso de Língua Espanhola oferecido no projeto de extensão "Núcleo de Línguas Adicionais" ao longo de seus quatro módulos, desde o nível básico até o intermediário. Portanto, não representam a totalidade do curso, mas sim um protótipo dele, ou seja, "estruturas flexíveis e vazadas que permitem modificações por parte 
daqueles que queiram utilizá-las em outros contextos que não os das propostas iniciais" (ROJO, 2012, p. 8).

Todas as unidades iniciam com uma atividade de préleitura, ou seja, uma atividade que introduz a leitura que será realizada, que prepara os alunos para o que será abordado e que também auxilia na recuperação de conhecimentos prévios sobre o tema ou o gênero discursivo proposto. As atividades de pré-leitura presentes no material são questões introdutórias que servem para nortear discussões iniciais, pequenos textos que contêm as informações que serão trabalhadas na unidade, algum tópico gramatical específico, como o uso do verbo "llevar" para referir-se ao que se está vestindo, ou alguma imagem que remeta ao tema proposto. A unidade 10, por exemplo, que tem como temática os sonhos, os desejos para o futuro, tem a seguinte atividade de pré-leitura (Figura 2):

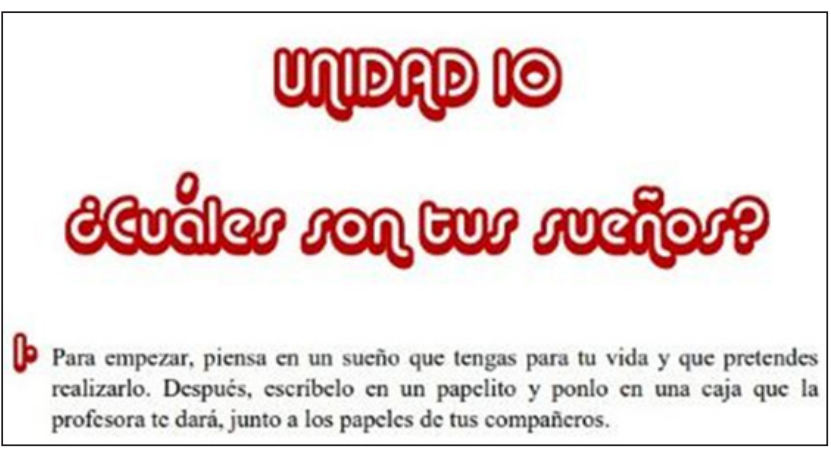

Figura 2. Atividade de pré-leitura da unidade 10 do material apresentado em Pinho (2015b).

A atividade pede que cada aluno pense em um sonho e escreva-o em um papel, que seria guardado em uma caixa pela professora, sem identificar-se. Dessa forma, o aluno já inicia a aula imerso no tema que se pretende tratar, pois precisa acionar sua rede de conhecimentos prévios sobre o tema, importante para a consolidação da aprendizagem, e relacioná-los com sua própria experiência, já que a memória tem origem na experiência, conforme Cammarota, Bevilaqua e Izquierdo (2015). Além disso, o que for trabalhado a seguir, que também trata de desejos e sonhos, será conectado a essa rede mental do conhecimento por meio dessa primeira informação.

A seguir, nessa mesma unidade, é feita a leitura de um conto em primeira pessoa que trata dos sonhos de um menino venezuelano para ele e para seu país, seguida de questões que buscam promover a reflexão sobre o contexto a partir do qual o narrador fala, os tipos de sonhos que o menino descreve e as impressões pessoais dos alunos sobre o texto apresentado. Depois, é introduzido o tópico gramatical da unidade, o presente do subjuntivo, usado para expressar desejos, sonhos e possibilidades no futuro. Retoma-se o uso desse tempo verbal no texto e são feitos exercícios que envolvem a temática da aula. Por fim, a atividade de pré-leitura é retomada para que, após as reflexões e a troca de ideias feitas em aula, cada aluno reflita sobre o que escreveu no papel e, além disso, digam o que desejam para os colegas no futuro. Assim, evocase a informação anterior para pensar nela com um olhar diferente, já que neste momento as redes neurais ativadas para pensar nos sonhos adquiriram outras informações, que são diferentes para cada um, pois cada um possui experiências diferentes que influenciam sua memória.

Cada unidade apresenta também uma ou mais leituras de diferentes gêneros discursivos: propaganda, entrevista, artigo de moda, artigo de divulgação científica, lenda, notícia, conto e poema. Como já foi mencionado, apesar de a leitura ser o eixo norteador das unidades, as quatro habilidades linguísticas eram trabalhadas nas atividades relacionadas aos textos. Essas atividades foram pensadas a partir das funções cognitivas, algumas exigem que uma ou mais sejam acionadas para a realização das tarefas e outras, além disso, foram feitas para exercitar alguma função cognitiva específica.

Na unidade quatro, é apresentado um artigo de divulgação científica sobre a relação entre neurociência e educação. Assim como nas demais unidades, há uma atividade de pré-leitura. Porém, é possível que o tema não seja tão familiar a todos os alunos, além de o texto tratar de vários conceitos que podem ser novos para os seus leitores ao mesmo tempo. Tendo em vista as possíveis dificuldades de leitura que esses aspectos poderiam causar, foi proposta a elaboração de um mapa conceitual com os principais conceitos e a relação de ideias apresentadas no texto, como uma estratégia para superar esse problema.

No mapa conceitual, o aluno pode destacar as informações mais importantes ou os conceitos-chave, criar conexões entre eles e organizar os tópicos que geraram mais dificuldade durante a leitura. Assim, o mapa funcionaria como um auxílio no momento de recuperar as informações do texto. O processo de construção do mapa exercita a atenção, já que o aluno precisa direcionar sua consciência para aquilo que é mais importante e deixar em segundo plano as informações menos importantes. Ele também exige que a memória de trabalho seja exercitada, pois é preciso lidar com várias informações ao mesmo tempo para estabelecer relações entre os conceitos, de modo que o mapa fique conciso, organizado, e que tenha informações suficientes. Além disso, o formato do mapa, que segue a mesma forma como as memórias são organizadas no nosso cérebro, contribui para fortalecer o registro que será feito, pois é preciso retomar várias vezes as informações mais importantes, e a repetição do uso das informações, associada com os registros que já existem, contribui para esse reforço, de acordo com Cosenza e Guerra (2011). 
$\mathrm{Na}$ unidade 7 do material, que tem como tema lendas que contam histórias de lugares, cujo texto principal é uma lenda boliviana que explica a história de uma montanha. As atividades finais da unidade estão apresentadas na Figura 3.

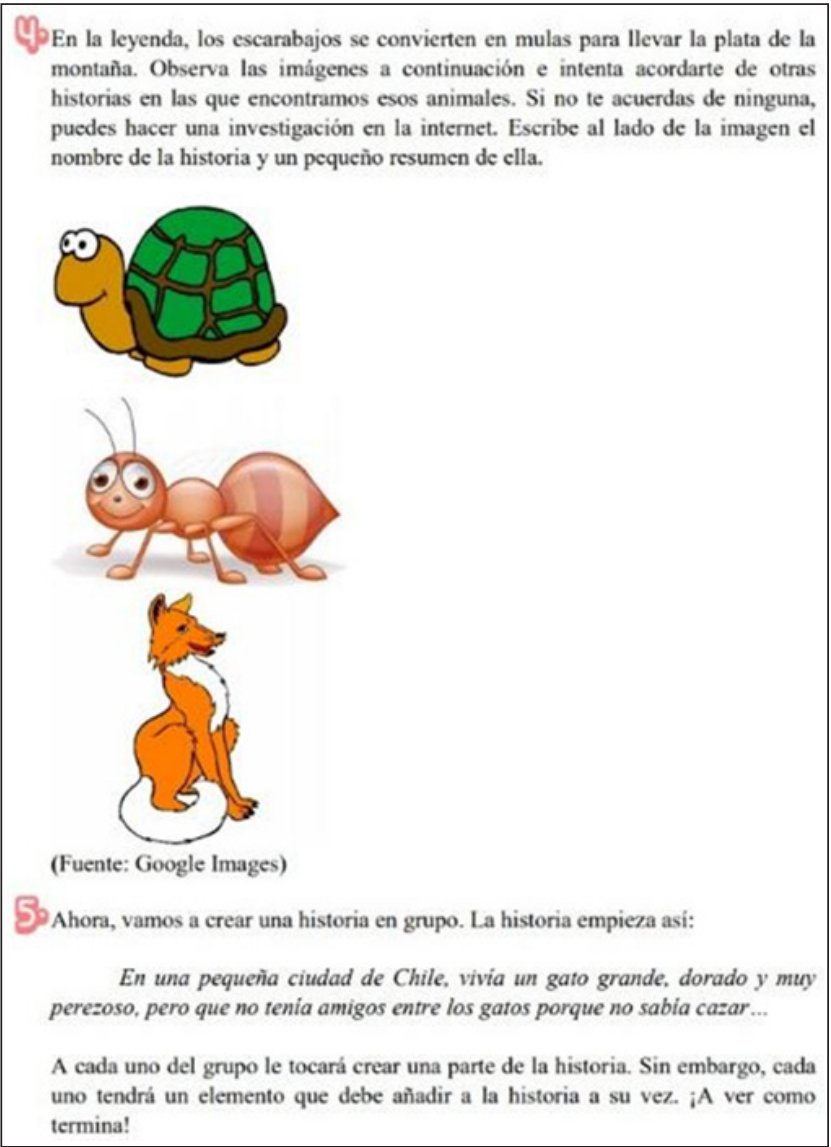

Figura 3. Atividades finais da unidade 7 do material apresentado em Pinho (2015b).

A primeira atividade (exercício 4) pede que os alunos tentem lembrar-se de outras lendas ou fábulas nas quais os personagens sejam os animais mostrados nas imagens. Os alunos precisam recorrer à memória de longa duração e recuperar as lendas que conhecem para selecionar entre elas o que foi solicitado. Isso requer um conhecimento do gênero lenda, de suas características, para que sejam recuperados apenas aqueles textos que podem ser úteis na atividade, o que além de ser um exercício de memória, também exercita a atenção. Caso o aluno não se lembre de nenhuma lenda, o enunciado orienta a fazer uma pesquisa na internet, o que também exige atenção seletiva, ou seja, ser capaz de voltar a atenção a um foco, neste caso as lendas com os animais indicados, e ignorar os demais.

Além de identificar as histórias solicitadas, o exercício solicita que o aluno as conte de forma resumida. Para tanto, é necessário recuperar os fatos mais importantes da história e usar a memória de trabalho para organizar todas as informações, selecionando as mais importantes e deixando outras de lado, sem perder o sentido da história. A função expressiva também é fundamental para a realização do exercício, pois o texto precisa ter coerência, clareza, organização e correção linguística, além de ser adequado ao contexto e respeitar as características do gênero.

Depois de exercitar a memória e a produção escrita de histórias que têm animais como personagens, que podem ser lendas, como no texto da unidade, ou fábulas, o exercício seguinte pede outra produção um pouco mais complexa que a anterior. Trata-se de uma produção oral coletiva em que cada membro do grupo cria uma parte, em sequência. O exercício dá o início da história e cada um, em seu turno, dá continuidade à história. Não há muito tempo para planejar, nem é possível usar o suporte da escrita, já que tudo é feito oralmente. Além disso, cada membro do grupo recebe um elemento diferente (uma escova de cabelo, um livro, uma fruta ou outro objeto) que deve introduzir na história. O personagem principal da história também é um animal, um gato, por isso também é preciso recuperar o que sabem sobre os gêneros lenda e fábula para que a história criada tenha as mesmas características.

Esse exercício exige atenção sustentada, pois os alunos precisam manter o foco na história que está sendo criada sem desviar-se dela em nenhum momento e buscar memorizar os fatos que estão sendo criados, já que precisa conhecer tudo o que está sendo criado para que sua parte tenha sentido em relação às outras. As funções executivas também são exercitadas, já que o aluno necessita da memória de trabalho para lidar com várias informações ao mesmo tempo, precisa planejar a sua parte da história, levando em consideração o que já foi criado, o elemento que precisa acrescentar sem interromper o fluxo da história e possibilitar uma continuidade coerente, ou seja, deve ter "capacidade de abstração, de tomar decisões e gerar alternativas" (MAIA; COSTA, 2011, p. 56). Posteriormente, é preciso usar a linguagem (função expressiva) para elaborar o trecho da história, seguindo o mesmo estilo e forma dos trechos anteriores. A criação espontânea e improvisada é uma estratégia que resulta muito positiva no ensino da Língua Adicional, já que em situações reais de comunicação o indivíduo não terá tempo de consultar nenhuma fonte, ou apoiar-se em algum suporte. É preciso pensar e organizar suas ações rapidamente, como na atividade 5 .

$\mathrm{Na}$ unidade 8 do material também temos exemplos de atividades que utilizam estratégias para exercitar as funções cognitivas, como podemos ver na Figura 4. 


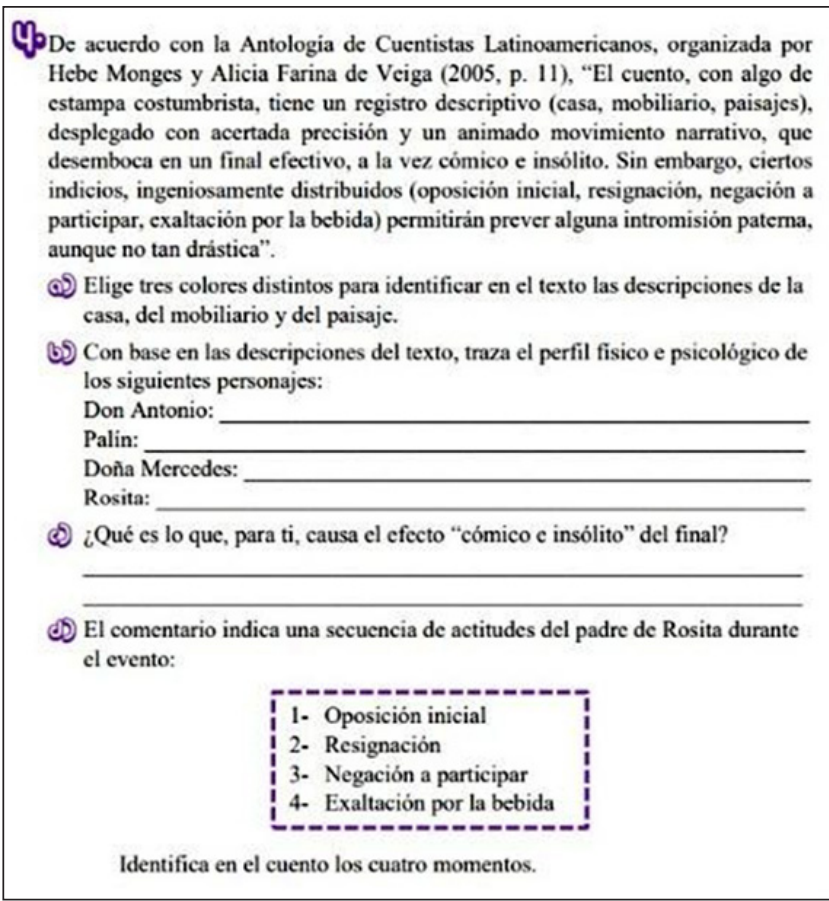

Figura 4. Atividades da unidade 8 do material apresentado em Pinho (2015b).

As atividades observadas na Figura 4 são referentes ao conto "Los novios", do escritor Adolfo Herrera García. A introdução dos exercícios apresenta o trecho de uma análise teórica feita sobre o referido conto, na qual apresenta algumas características que se destacam no texto. A primeira atividade pede que as características do espaço apresentadas no trecho sejam destacadas com cores no conto. O aproveitamento de diferentes canais sensoriais no cérebro, como o visual, neste caso, é importante para fortalecer os traços de memória, ou seja, torná-la mais durável, segundo Cosenza e Guerra (2011). A atividade seguinte pede que sejam traçados os perfis físicos e psicológicos de quatro personagens do conto. Diferentemente da primeira atividade, na qual só é preciso localizar as informações no texto, voltando a atenção para elas, nesta além de localizar as informações, é necessária a compreensão leitora, já que nem todos os personagens listados têm características descritas de forma explícita no texto, mas sim expressas por meio de suas atitudes.

Ambas as atividades exercitam as funções executivas, pois exigem que as informações sejam selecionadas, organizadas, processadas para, a partir delas, dar as respostas da atividade seguinte, que são dizer o que causa o efeito cômico e insólito do final do conto, o que só é possível conhecendo as características do espaço e dos personagens envolvidos. Por fim, o aluno deve organizar as ações de um dos personagens durante o conto, o que também ajuda muito na compreensão da totalidade do texto. As informações assim selecionadas funcionam como estratégia da mesma forma que o mapa solicitado na atividade da unidade 4, discutido anteriormente. Elas fazem parte da estrutura formal do texto e, dessa forma, pode-se recuperá-las mais rapidamente para compreender cada fato apresentado.

Todas as unidades, apesar de não serem iguais, de não seguirem uma sequência fixa de tipos de atividades iguais, até mesmo por terem objetivos diferentes, possuem elementos em comum, como uma leitura norteadora, atividades de pré-leitura e no mínimo uma produção oral ou escrita. Além disso, entre a leitura e a produção há atividades estratégicas que exercitam as funções cognitivas de forma explícita, ou seja, imitam a forma como essas funções ocorrem no cérebro, de modo que o aprendiz pode ter consciência do próprio processo e, assim, exercitá-lo e aprimorá-lo cada vez mais.

\section{Considerações finais}

Apresentamos, neste artigo, uma análise de algumas atividades de um material didático elaborado para o ensino de Língua Espanhola como língua adicional, a partir da Neurociência Cognitiva. O objetivo deste trabalho era verificar como as atividades e estratégias apresentadas poderiam contribuir para o exercício das funções cognitivas e para o ensino e aprendizagem de leitura em Língua Espanhola. Foram discutidas oito atividades de quatro unidades diferentes. Buscamos mostrar como, em cada uma das atividades, as funções cognitivas foram exercitadas nos exercícios de compreensão leitora e de que maneira isso acontece em cada um deles.

Foi possível verificar que as atividades analisadas exercitam as funções cognitivas em conjunto, algumas de forma mais evidente, outras não. Também verificamos que algumas delas funcionam da mesma maneira como determinada função cognitiva funciona no nosso cérebro ao realizarmos a leitura, o que serve como estratégia para a aprendizagem e também para a realização de outras atividades dentro da mesma unidade, tornando o trabalho mais eficiente. $\mathrm{O}$ uso dessas atividades estratégicas pode solucionar problemas que os alunos encontrem na realização de determinada leitura ou produção, permitindo assim a realização de tarefas de maior complexidade.

As atividades descritas podem ser modificadas e adaptadas para outros temas ou outros aspectos linguísticos, sem que a sua estrutura seja modificada e, assim, pode-se trabalhar a mesma função cognitiva em outros contextos. Por isso, acreditamos que o conhecimento dessas estruturas e de seu funcionamento pode ser útil a outros professores que desejem buscar 
estratégias para o ensino de leitura em língua adicional considerando as etapas que o cérebro humano percorre no processo de aprendizagem.

\section{Referências}

BAKHTIN, Mikhail. Estética da criação verbal. 6. ed. São Paulo: WMF Martins Fontes, 2011.

CAMMAROTA, Martín; BEVILAQUA, Lia; IZQUIERDO, Iván. Aprendizado e memória. In: LENT, Roberto (Org.). Neurociência da mente e do comportamento. Rio de Janeiro: Guanabara Koogan, 2015. p. 241-252.

COZENZA, Ramon M.; GUERRA, Leonor B. Neurociência e educação: como o cérebro aprende. Porto Alegre: Artmed, 2011.

DAMÁSIO, António. O mistério da consciência. São Paulo: Companhia das letras, 2000.

FROST, Ram. Sistemas ortográficos e processos de reconhecimento de palavras na leitura. In: SNOWLING, M.; HULME, C. (Orgs.). A ciência da leitura. Porto Alegre: Penso, 2013. p. 290-313.

LEFFA, Vilson J. Aspectos da leitura: uma perspectiva psicolinguística. Porto Alegre: Sagra: DC Luzzato Editores, 1996.

LEFFA, Vilson J.; IRALA, Valesca B. O ensino de outra(s) língua(s) na contemporaneidade. In: LEFFA, V. J.; IRALA, V. B. Uma espiadinha na sala de aula: ensinando línguas adicionais no Brasil. Pelotas: Educat, 2014. p. 21-48.

LENT, Roberto. Cem bilhões de neurônios: conceitos fundamentais de Neurociência. 2. ed. São Paulo: Atheneu, 2010.

LENT, Roberto. Neuroplasticidade. In: LENT, Roberto (Org.). Neurociência da mente e do comportamento. Rio de Janeiro: Guanabara Koogan, 2015. p. 241-252.

MAIA, Heber. Funções cognitivas e aprendizado escolar. In.: MAIA, Heber (Org.). Neurociencias e desenvolvimento cognitivo. 2. ed. Rio de Janeiro: Wak Editora, 2011. p. 55-62. (Coleção Neuroeducação, 2).
MAIA, Heber; COSTA, Célia Regina Carvalho Machado da Costa. Funções executivas. In: MAIA, Heber (Org.). Neurociências e desenvolvimento cognitivo. 2. ed. Rio de Janeiro: Wak Editora, 2011. p. 55-62. (Coleção Neuroeducação, 2)

PINHO, Louise Silva do. Filosofia Bakhtiniana da Linguagem e Neurociências em diálogo: uma proposta para o ensino de leitura em Lingua Espanhola. 2015. 194 f. Dissertação (Mestrado) - Universidade Federal do Pampa, Bagé, RS, 2015a. Disponível em: <http://cursos.unipampa.edu.br/cursos/ profelinguas/files/2017/05/filosofia-bakhtiniana-da-linguageme-neurociencias-em-dialogo.pdf $>$. Acesso em: 27 set. 2017.

PINHO, Louise Silva do. !Léelo ahora! Prácticas de lectura en lengua española. 2015. 55 f. Produto pedagógico (Mestrado) Universidade Federal do Pampa, Bagé, RS, 2015b. Disponível em: <http://cursos.unipampa.edu.br/cursos/profelinguas/ files/2017/05/leelo-ahora--practicas-de-lectura-en-lenguaespanola.pdf>. Acesso em: 27 set. 2017.

RELVAS, Marta Pires. Neurociência na prática pedagógica. Rio de Janeiro: Wak Editora, 2012.

ROJO, Roxane. Protótipos didáticos para os multiletramentos. In: ROJO, Roxane; MOURA, Eduardo (Orgs.). Multiletramentos na escola. São Paulo: Parábola Editorial, 2012. p. 7-9.

SCHLATTER, Margarete. O ensino de leitura em língua estrangeira na escola: uma proposta de letramento. In: Calidoscópio. Revista de Linguística Aplicada, São Leopoldo: Unisinos, v. 7, n. 1, p. 11-23, jan./abr. 2009. Disponível em: <revistas.unisinos.br/index.php/calidoscopio/article/ view/4851/2109>. Acesso em: 18 abr. 2018.

SCHLATTER, Margarete; GARCEZ, Pedro de Moraes. Línguas Adicionais na escola: aprendizagens colaborativas em inglês. Erechim: Edelbra, 2012.

Recebido: 27/09/2017

Aprovado: 08/01/2018

Contato:

Louise Silva do Pinho <louisepinho0@gmail.com> 